\title{
Relation of urinary cotinine concentrations to cigarette smoking and to exposure to other people's smoke
}

\author{
S G Thompson, R Stone, K Nanchahal, N J Wald
}

\begin{abstract}
The relation of urinary cotinine measurements to tobacco consumption in smokers and to exposure to other people's smoke in non-smokers was studied in 49 smokers and 184 reported non-smokers attending a health screening centre. The median urinary cotinine concentration was $1623 \mathrm{ng} / \mathrm{ml}^{\star}$ in the smokers and $6.1 \mathrm{ng} / \mathrm{ml}$ in the nonsmokers. In smokers the average urinary cotinine concentration increased with reported habitual cigarette consumption; in non-smokers it increased with the reported total seven day duration of exposure to other people's tobacco smoke. Cotinine concentrations were approximately three times higher in non-smokers living with a spouse or partner who was a smoker than in those living with a non-smoker; their reported duration of exposure to tobacco smoke was also three times higher. Nonsmoking subjects who were exposed to any tobacco smoke and who lived with a smoker reported $70 \%$ of their exposure to be at home $(56 \%$ for men and $86 \%$ for women); the men reported more exposure at work than non-smoking men who lived with a non-smoker. This study confirms the relation of urinary cotinine to stated tobacco smoke exposure in both smokers and non-smokers and further validates the use of information on the smoking habits of the spouse or partner as a measure of tobacco smoke exposure in epidemiological studies of nonsmokers.
\end{abstract}

The potential health risks to non-smokers of other people's tobacco smoke have received much attention. Major reports on such "passive smoking" have been compiled by national research organisations in several countries, including the United States, ${ }^{1}$ Australia, ${ }^{2}$ and the United Kingdom, ${ }^{3}$ and the issue is of concern to politicians and the general public. A review of the epidemiological studies of the effect of passive smoking on lung cancer risk ${ }^{4}$ concluded that the risk might be $30 \%$ higher in non-smokers living with smokers than in non-smokers living with non-smokers.

One problem with epidemiological studies of passive smoking is the lack of a good measure of exposure. Recall of habitual or recent exposure to environmental tobacco smoke may be imprecise and inaccurate and the measure used in most epidemiological studies, whether or not the subject lives with a smoker, may appear to be crude. It has, however, been validated by measurements of urinary cotinine, a metabolite of nicotine; in non-smoking men who reported exposure to other people's tobacco smoke and unexposed non-smoking men who reported no exposure, urinary cotinine concentration was a sensitive and specific marker of exposure to other people's tobacco smoke. ${ }^{56}$

The present study was designed (1) to obtain cotinine data on women as well as men; (2) to determine the places where non-smokers are exposed to other people's tobacco smoke; and (3) to check earlier results on the validity of using the smoking habit (smoking versus non-smoking) of the person a nonsmoker lives with as a measure of the exposure to other people's tobacco smoke.

\section{Methods}

SUBJECTS

We studied 233 men and women attending the BUPA Medical Centre in London on specific days. Smokers completed a questionnaire on their smoking habits and non-smokers on their exposure to other people's smoke. Nonsmokers were asked if they had been exposed to other people's tobacco smoke during the past seven days (including the day of attendance); if they had, they were asked about duration (how long the smoke could be smelt) and places of exposure.

\section{COTININE ASSAY}

A urine sample was obtained and frozen at $-40^{\circ} \mathrm{C}$ until analysis. Urinary cotinine was measured by means of a radioimmunoassay ${ }^{7}$ modified to improve the reproducibility for measurements in urine samples. Bovine serum albumin $0.1 \%$ (Sigma Chemical Company, Dorset) was added to the assay buffer and a second antibody used to separate the bound fraction (ILS, London). Samples from smokers were diluted 20 fold and a $0.01 \mathrm{ml}$ sample assayed. To increase the sensitivity of the assay to detect cotinine in the urine of nonsmokers, the volume of the sample to be assayed was increased to $0.1 \mathrm{ml}$. To check that accuracy was maintained between the different versions of the assay, a urine pool from samples

*Conversion to SI units for cotinine: $1 \mathrm{ng} / \mathrm{ml}=5.68$ nmol/l. 
Table 1 Urinary cotinine concentrations in 49 smokers and 184 non-smokers

\begin{tabular}{lcccc}
\hline & $\begin{array}{l}\text { No of } \\
\text { subjects }\end{array}$ & \multicolumn{3}{l}{ Urinary cotinine concentration $(\mathrm{ng} / \mathrm{ml})$} \\
\cline { 3 - 5 } & & Median & Arithmetic mean & Range \\
\hline SMOKERS & 9 & 1390 & & \\
$\quad$ Men & 40 & 1652 & 2050 & $52-6810$ \\
Women & 49 & 1623 & 1610 & $3-4443$ \\
All & & & 1691 & $3-6810$ \\
NON-SMOKERS & 85 & $6 \cdot 7$ & & \\
Men & 99 & $5 \cdot 9$ & $19 \cdot 7$ & $0 \cdot 3-392$ \\
Women & 184 & $6 \cdot 1$ & $13 \cdot 0$ & $0 \cdot 3-34$ \\
All & & & & $0 \cdot 3-392$ \\
\hline
\end{tabular}

from smokers was diluted serially (a cotinine free pool prepared from samples from nonsmokers being used as diluent) until the cotinine concentrations were in the range seen in the non-smokers; cotinine was then measured with both assays. The sensitive "non-smokers" assay was accurate for cotinine concentrations of $1-25 \mathrm{ng} / \mathrm{ml}$ while the "smokers" assay was accurate in the range $25-250 \mathrm{ng} / \mathrm{ml}$. Considerable care was devoted to establishing relative accuracy within and between assays because of the importance of making a valid comparison of cotinine concentrations in smokers and nonsmokers, a comparison that spans three orders of magnitude. The between batch coefficient of variation (CV) for the "smokers" assay was $6 \%$; for the "non-smokers" assay the CV was $10 \%$ for urinary cotinine concentrations of 20 $\mathrm{ng} / \mathrm{ml}$ and $20 \%$ for concentrations of $5 \mathrm{ng} / \mathrm{ml}$. Urinary creatinine concentrations were measured by high performance liquid chromatography with a silica column with acetonitrile:methanol: $10 \%$ ammonia in a ratio of $840: 150: 10$ as mobile phase with ultraviolet detection at $254 \mathrm{~nm}$.

\section{STATISTICS}

Urinary cotinine concentrations in smokers were approximately normally distributed, whereas in non-smokers a logarithmic transformation of the cotinine concentrations was necessary to achieve approximate normality. Thus statistical analyses for non-smokers used transformed data, but results have been converted back to the untransformed scale for presentation. Since cotinine has a half life of about one day, we also performed an analysis that down weighted exposures reported several days before by a factor of 0.5 for each day between the exposure and the day the urine sample was collected. Adjustment for creatinine concentration was performed by linear regression of cotinine in smokers, or log cotinine in non-smokers, on creatinine. ${ }^{8}$ All the $p$ values presented are 2 -sided.

\section{Results}

The 49 smokers recruited had an average age of 42 (SD 11) years, and an average age at which they had started to smoke regularly of 19 (4) years. Three subjects currently smoked cigars only and one subject smoked filter cigarettes and cigars. The remaining 45 subjects smoked only filter cigarettes. Of the 184 non-smokers, 74 were ex-smokers and 110 reported that they were lifelong non-smokers. The average age of the non-smokers was 46 (11) years.

The median urinary cotinine concentration was $1623 \mathrm{ng} / \mathrm{ml}$ in the smokers and $6.1 \mathrm{ng} / \mathrm{ml}$ in the non-smokers. Median values for smokers and non-smokers were similar for men and women (table 1). There was some overlap in the

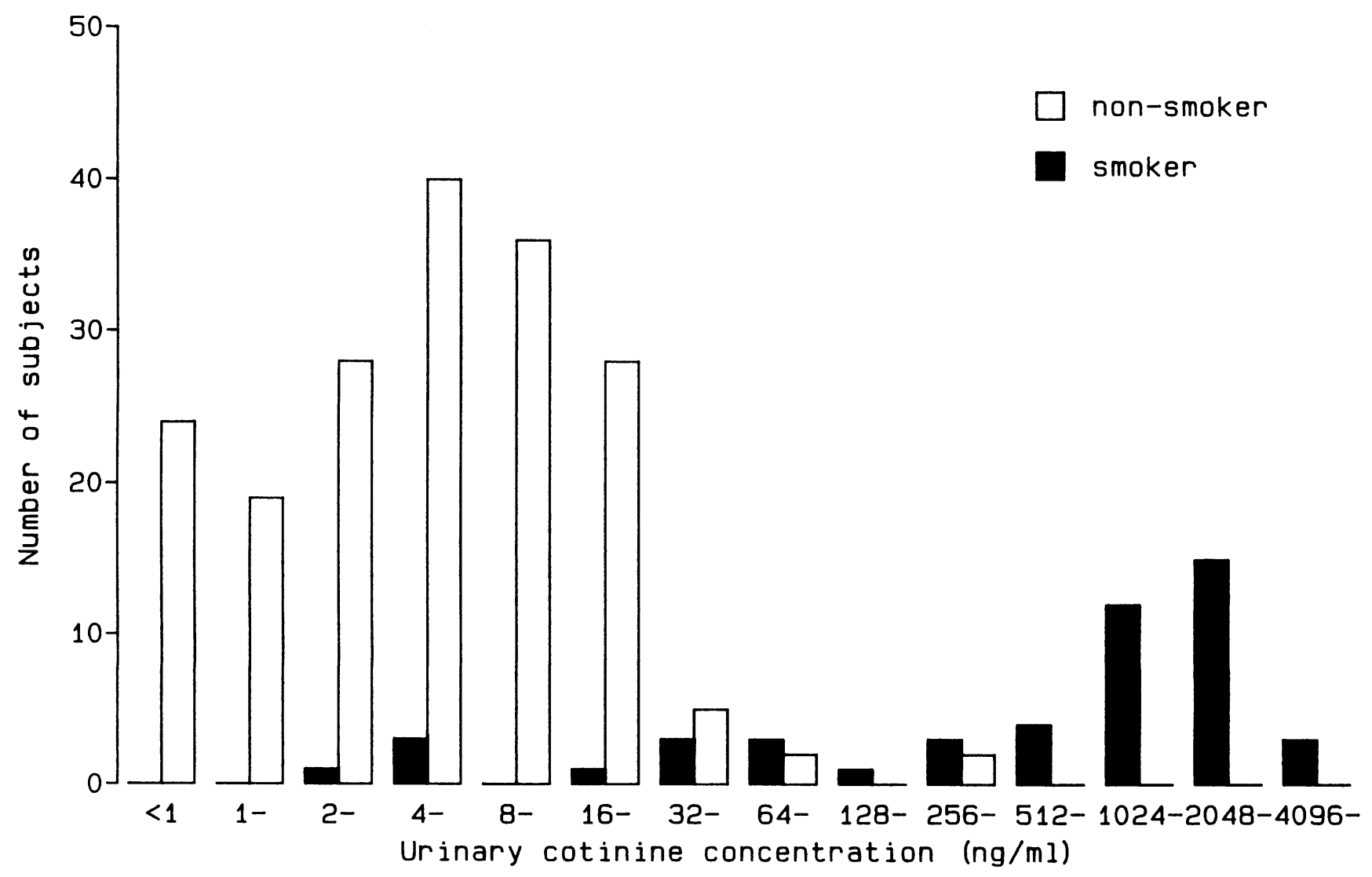

Figure 1 Distributions of urinary cotinine concentrations in 49 reported smokers and 184 reported non-smokers. 


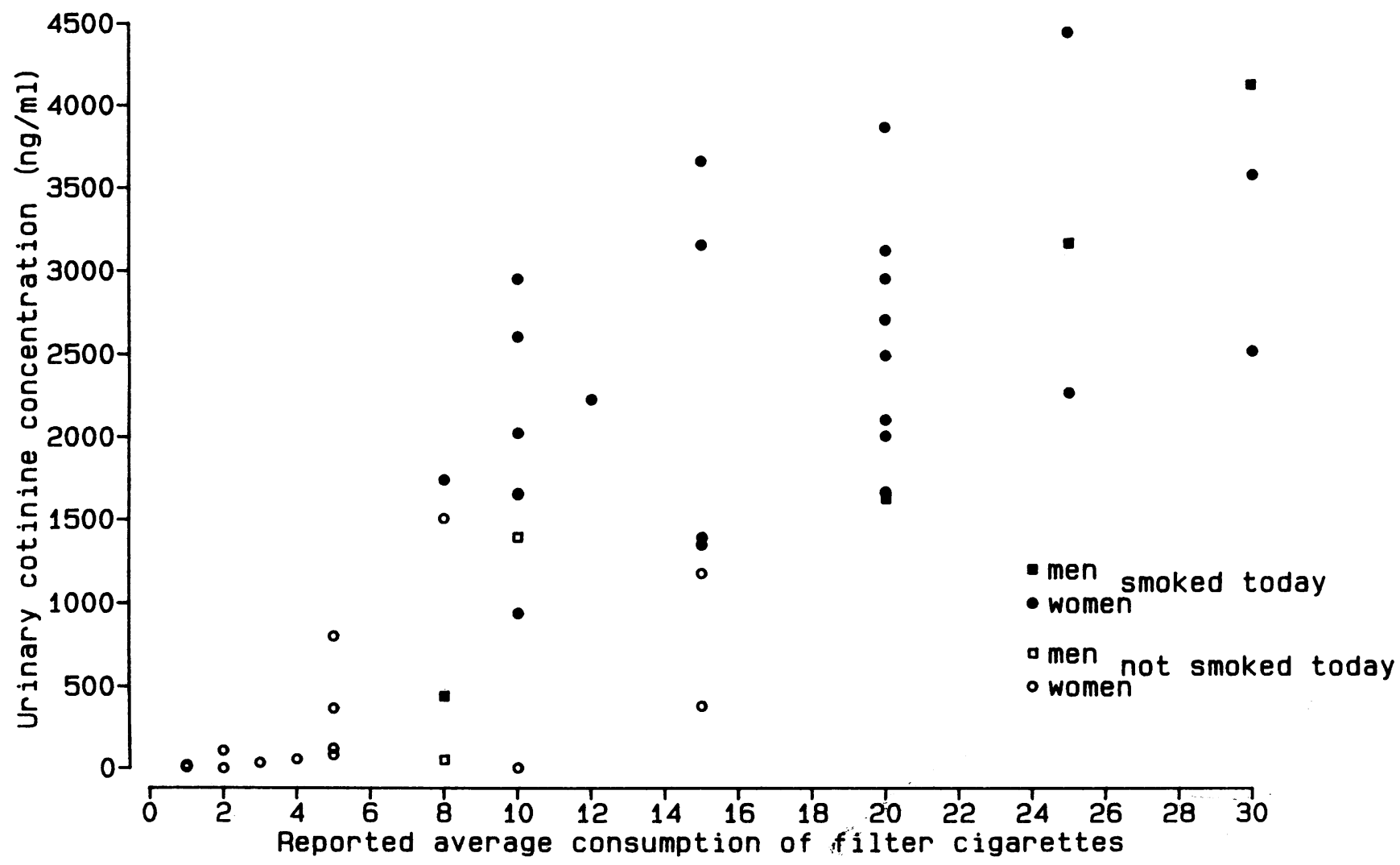

Figure 2 Urinary cotinine concentrations in relation to reported average cigarette consumption among 45 smokers of filter cigarettes alone.

distributions of cotinine concentrations between smokers and non-smokers (fig 1). The lowest cotinine concentrations in the smokers were generally in women who reported smoking only a few cigarettes a day and none on the day of the urine collection (fig 2). Only three $(1.6 \%)$ of the 184 reported non-smokers had cotinine concentrations above $100 \mathrm{ng} / \mathrm{ml}$. Two of these subjects reported no tobacco smoke exposure in the preceding seven days whereas the other reported 101 hours; their cotinine concentrations were 117,393 , and $328 \mathrm{ng} / \mathrm{ml}$.

There was a linear relation between urinary cotinine concentrations and reported habitual consumption of cigarettes for the $\mathbf{4 5}$ smokers of filter cigarettes alone, with an estimated increase in cotinine of 126 (SE 14) $\mathrm{ng} / \mathrm{ml}$ per cigarette smoked ( $p<0.001$; fig 2). Adjustment for creatinine concentration changed the estimated increase to 132 (14) $\mathrm{ng} / \mathrm{ml}$ per cigarette smoked.

There was no significant difference in the geometric mean cotinine concentrations be- tween ex-smokers $(5.6 \mathrm{ng} / \mathrm{ml})$ and reported lifelong non-smokers $(4.6 \mathrm{ng} / \mathrm{ml}, \mathrm{p}>0 \cdot 2)$. Of the non-smokers, 53 reported no exposure to tobacco smoke in the preceding week; they had a geometric mean cotinine concentration of 3.7 $\mathrm{ng} / \mathrm{ml}$, compared with $5.7 \mathrm{ng} / \mathrm{ml}$ in the other 131 non-smokers. Further subdivision according to the extent of reported exposure is shown in table 2 . Increases in geometric mean cotinine concentrations were observed only in the upper two quintiles of exposure duration (average durations 11 and 34 hours). A linear regression of $\log$ cotinine concentration on duration of exposure (with the subject who reported 101 hours of exposure omitted) showed that cotinine concentrations increased by an average of $44 \%(95 \%$ confidence interval $23-67 \%$, $\mathrm{p}<0.001$ ) for each increase of 10 hours in reported exposure (fig 3). The correlation between log urinary cotinine concentration and reported total duration of exposure was 0.33 . When the reported exposures were weighted to adjust for cotinine half life the correlation

Table 2 Urinary cotinine concentrations in non-smokers according to total reported duration of exposure to tobacco smoke within the past seven days (including the day the urine sample was collected)

\begin{tabular}{|c|c|c|c|c|c|}
\hline \multicolumn{3}{|c|}{ Duration of exposure } & \multirow[b]{2}{*}{ No of subjects } & \multicolumn{2}{|c|}{ Cotinine concentration $(\mathrm{ng} / \mathrm{ml})^{\star}$} \\
\hline$\underset{\text { group }}{\text { Quintile }}$ & Range (h) & Average ( $h$ ) & & $\begin{array}{l}\text { Geometric } \\
\text { mean }\end{array}$ & $\begin{array}{l}95 \% \text { confidence } \\
\text { interval }\end{array}$ \\
\hline $\begin{array}{l}1 \text { st } \\
\text { 2nd } \\
\text { 3rd } \\
\text { 4th } \\
5 \text { th }\end{array}$ & $\begin{array}{lr}0.0 & \\
0.02- & 2 \cdot 05 \\
2 \cdot 25- & 6.50 \\
6 \cdot 75-17.50 \\
18 \cdot 20-101\end{array}$ & $\begin{array}{l}0 \cdot 0 \\
1 \cdot 08 \\
4 \cdot 28 \\
10 \cdot 75 \\
34 \cdot 10\end{array}$ & $\begin{array}{l}53 \\
32 \\
33 \\
33 \\
33\end{array}$ & $\begin{array}{r}3.7 \\
3.9 \\
3.8 \\
5.2 \\
13.5\end{array}$ & $\begin{array}{l}2.5 \text { to } 5.4 \\
2.5 \text { to } 5.9 \\
2.4 \text { to } 5.9 \\
3.4 \text { to } 8.1 \\
9.3 \text { to } 19.8\end{array}$ \\
\hline All & $0-101$ & & 184 & $5 \cdot 0$ & 4.1 to 6.1 \\
\hline
\end{tabular}

*Corresponding median values in the $1 \mathrm{st}-5$ th quintiles were $4 \cdot 0,3 \cdot 8,4.0,7 \cdot 6$, and $16 \mathrm{ng} / \mathrm{ml}$ respectively. Arithmetic means were $15,6 \cdot 9,7 \cdot 2,9 \cdot 4$, and $27 \mathrm{ng} / \mathrm{ml}$; the arithmetic mean for the $1 \mathrm{st}$ quintile group excluding the two subjects with cotinine values greater than $100 \mathrm{ng} / \mathrm{ml}$ (see text) was $5.6 \mathrm{ng} / \mathrm{ml}$. 


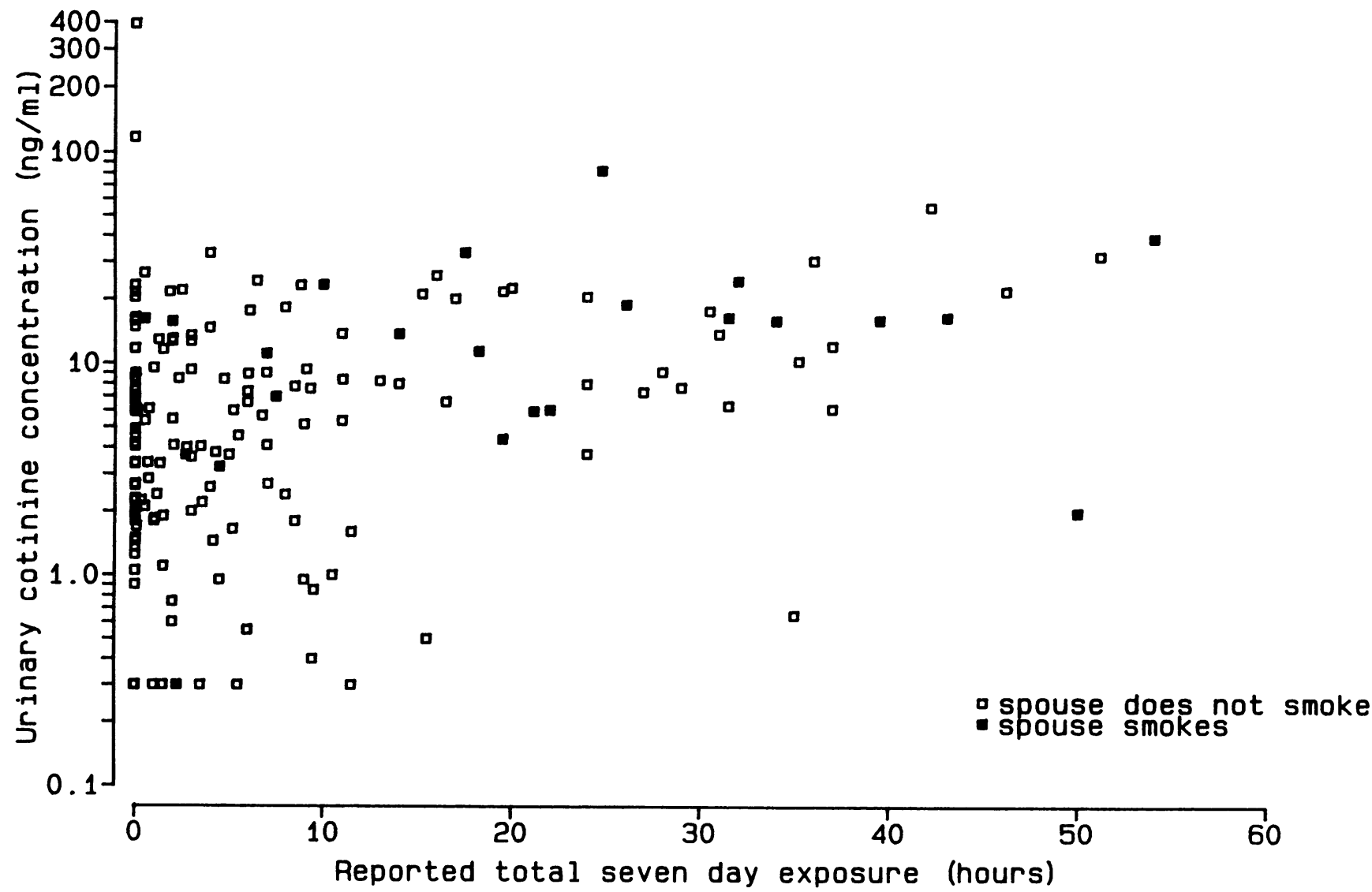

Figure 3 Urinary cotinine concentrations in relation to reported total seven day exposure to tobacco smoke among 183 non-smokers (the subject with 101 hours' reported exposure and a urinary cotinine concentration of $328 \mathrm{ng} / \mathrm{ml}$ is excluded).

between log cotinine concentration and weighted exposure remained at $\mathbf{0 . 3 3}$.

There was a correlation between log urinary cotinine concentrations and urinary creatinine concentrations in the non-smokers $(r=0.51, p$ $<0.001$ ), creatinine thus explaining about a quarter of the observed variation in cotinine concentrations. After adjustment for creatinine concentration the estimated increase in cotinine concentration was $38 \%$ for each increase of 10 hours in reported exposure $(p<0.001)$, compared with the unadjusted estimate of $44 \%$.

The reported total hours of exposure within the past seven days and the urinary cotinine concentrations in non-smokers according to whether their spouse or partner smoked are shown in table 3. Both the reported exposure and the average cotinine concentration were about three times greater in non-smokers who lived with a smoker than in those who did not. The findings were similar for men and women.

The reported sources of exposure to tobacco smoke are described in more detail in table 4. Exposure at home accounted for an average of $70 \%$ of the total reported exposure for subjects who lived with a smoker $(56 \%$ for men and $86^{\circ}$ for women); the corresponding figure for subjects who did not live with a smoker was $13 \%$ (9\% for men and $16 \%$ for women). Thus non-smoking men living with a smoker obtained more of their exposure outside the home

Table 3 Urinary cotinine concentrations and reported duration of exposure to other people's smoke within the past seven days in non-smokers according to the current smoking habit of the person with whom they live

\begin{tabular}{|c|c|c|c|c|}
\hline \multirow{2}{*}{$\begin{array}{l}\text { Subjects and } \\
\text { smoking category of } \\
\text { person subject lives with }\end{array}$} & \multirow[b]{2}{*}{ No of subjects } & \multirow[b]{2}{*}{$\begin{array}{l}\text { Reported exposure ( } h \text { ) } \\
\text { mean (range) }\end{array}$} & \multicolumn{2}{|c|}{ Cotinine concentration $(\mathrm{ng} / \mathrm{ml})^{\star \star \star}$} \\
\hline & & & $\begin{array}{l}\text { Geometric } \\
\text { mean }\end{array}$ & $\begin{array}{l}95 \% \text { confidence } \\
\text { interval }\end{array}$ \\
\hline MEN & & & & \\
\hline $\begin{array}{l}\text { Non-smoker } \\
\text { Smoker }\end{array}$ & $\begin{array}{l}74 \\
11\end{array}$ & $\begin{aligned} 6.0 & (0-46) \\
28.9 & (0-101)\end{aligned}$ & $\begin{array}{r}5 \cdot 4 \\
20 \cdot 0\end{array}$ & $\begin{array}{l}4.0 \text { to } 7 \cdot 3 \\
8.9 \text { to } 45.4\end{array}$ \\
\hline WOMEN & & & & \\
\hline $\begin{array}{l}\text { Non-smoker } \\
\text { Smoker }\end{array}$ & $\begin{array}{l}84 \\
15\end{array}$ & $\begin{aligned} 7.5 & (0-51) \\
17.8 & (0-43)\end{aligned}$ & $\begin{array}{l}3.6 \\
7 \cdot 6\end{array}$ & $\begin{array}{l}2.7 \text { to } 4.9 \\
4.3 \text { to } 13.3\end{array}$ \\
\hline $\begin{array}{l}\text { ALL } \\
\text { Non-smoker } \\
\text { Smoker }\end{array}$ & $\begin{array}{r}158 \\
26\end{array}$ & $\begin{aligned} 6.8 & (0-51) \\
22.5 & (0-101)\end{aligned}$ & $\begin{array}{r}4 \cdot 4^{\star \star} \\
11 \cdot 4^{\star \star}\end{array}$ & $\begin{array}{l}3.6 \text { to } 5.4 \\
6.9 \text { to } 18.9\end{array}$ \\
\hline
\end{tabular}

\Subjects living alone are grouped with subjects who live with a non-smoker.

$\star \star P$ value for difference: $p=0.008$.

$\star \star \star M e d i a n$ values in the six categories were $6 \cdot 1,16,4 \cdot 8,7 \cdot 0,5 \cdot 6$, and $15 \mathrm{ng} / \mathrm{ml}$ respectively; arithmetic means were $15,51,7 \cdot 4,11$, 11 , and $28 \mathrm{ng} / \mathrm{ml}$. 
Table 4 Sources of reported exposure in 131 non-smokers exposed to other people's tobacco smoke within the past seven days according to the current smoking habit of the person with whom the subject lives*

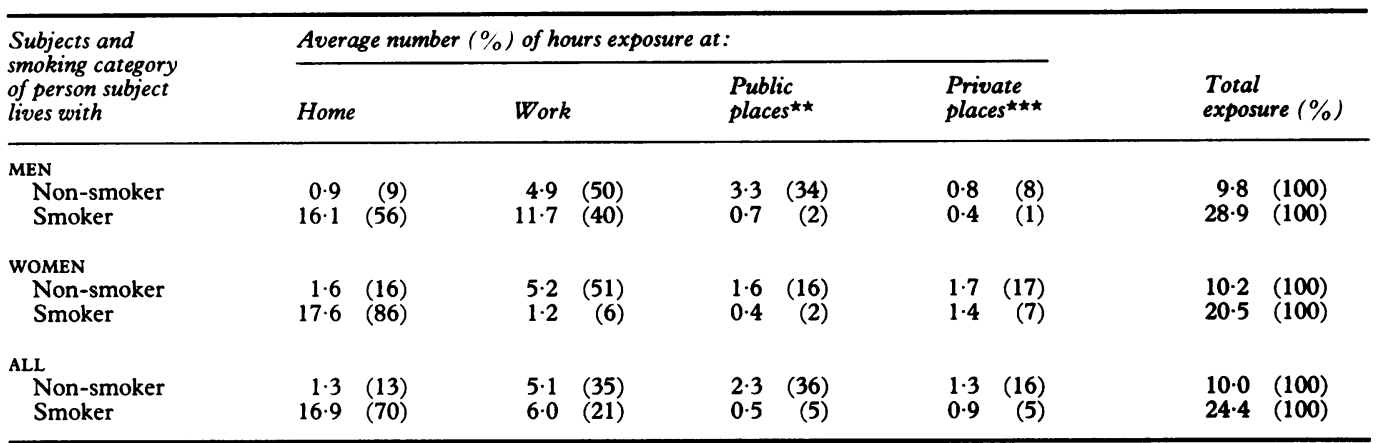

* Subjects living alone are grouped with subjects who live with a non-smoker.

$\star \star$ Public transport, public houses, and other public places.

$\star \star \star$ Private car, parties, and other sources.

than did non-smoking women living with a smoker. Exposure at work averaged $40 \%$ of the reported exposure for men but only $6 \%$ for women (the average number of hours of exposure being 11.7 and 1.2 respectively).

\section{Discussion}

This study showed a clear association between urinary cotinine concentration and the reported duration of exposure to other people's smoke, and confirms our previous study in men. ${ }^{5}$ Both male and female non-smokers who lived with a smoker had on average about three times the urinary cotinine concentration of other non-smokers. The arithmetic mean urinary cotinine concentrations (which may be the most appropriate summary measure in considering the consequent risk of lung cancer) for non-smokers who lived with a non-smoker, for other non-smokers, and for smokers were in the ratio $1: 3 \cdot 5: 140$ for men and $1: 1 \cdot 5: 220$ for women. The result for men is similar to the ratio of 1:3:200 in our earlier study. ${ }^{46}$ Considerable care was taken to establish the relative accuracy of the cotinine assay over the wide range of values seen in the study; the problem of gaining such relative accuracy routinely was seen in a recent interlaboratory quality assessment exercise. ${ }^{9}$

In epidemiological studies non-smokers living with smokers have been observed to have a $30 \%$ greater lung cancer risk than non-smokers living with non-smokers. ${ }^{4}$ The threefold difference in urinary cotinine concentrations between these groups can be used to estimate that non-smokers living with smokers have a 53\% greater risk of lung cancer than non-smokers who are completely unexposed to environmental tobacco smoke. ${ }^{4}$

In our present study non-smoking men who lived with a smoker not only reported greater exposure to tobacco smoke in the home than did non-smoking men not living with a smoker but also a greater exposure at work. This was similar to our previous result ${ }^{6}$ and explains why a measure of exposure based on the smoking habits of the spouse or partner may be a more sensitive indicator of environmental tobacco smoke exposure than it might at first appear. The finding was not, however, seen among the women in this study, perhaps because of the small numbers.
The overall relation between cotinine concentrations and reported duration of tobacco smoke exposure in the non-smokers was significant, though the correlation was not strong. This may have been due to variability in urinary cotinine concentrations (due to the arbitrary time of urine collection, with no fixed relation to recent exposure) and in the reporting of exposure (due to failure of accurate recall of duration and the lack of any measure of the intensity of exposure). The down weighting of durations of exposure further away from the time of urine collection was expected to increase the correlation with cotinine concentrations. That it did not do so was unexpected, but may have been due to the combination of a consistency between the exposures reported for the same individuals on different days (as had been found in other circumstances ${ }^{10}$ ) and the play of chance, resulting in particular from the large amount of variability in the measurements.

The overlap in the distributions of urinary cotinine concentrations in smokers and nonsmokers was greater than the overlap we found in our previous study in men. ${ }^{5}$ This could be due to the fact that some women smoked only a few cigarettes each day and had not smoked on the day of the urine collection. Three subjects who said they were non-smokers had urinary cotinine concentrations above $100 \mathrm{ng} / \mathrm{ml}$. Two of them reported no tobacco smoke exposure and one a total seven day exposure of 101 hours. It seems likely that the first two subjects failed to report either very extensive passive exposure or occasional active smoking. The third subject's cotinine concentration is plausible if the reported exposure is considered correct. On the basis of the distribution of cotinine concentrations none of the reported non-smokers could be considered a typical smoker. The lack of typical smokers misreporting themselves as non-smokers strengthens the argument that the observed excess lung cancer risk in epidemiological studies is unlikely to be due to the misclassification of smokers as non-smokers. ${ }^{4}$ The hypothesis ${ }^{11}$ that the excess lung cancer risk observed in the epidemiological studies could be completely explained by such misclassification required that $1.4 \%$ of self reported never smokers were regular current smokers and that $1 \cdot 1 \%$ were occasional current smokers. The information provided by the 
present study is important therefore as it strongly suggests that this hypothesis is untenable.

We thank Dr J Stock for administering the questionnaire and collecting the samples in this study.

1 National Research Council. Environmental tobacco smoke: measuring exposures and assessing health effects. Washington DC.

2 National Health and Medical Research Council. Effects of passive smoking on health. Canberra: Australian Government Publishing Service, 1987.

3 Independent Scientific Committee on Smoking and Health. Fourth report. London: HMSO, 1988

4 Wald NJ, Nanchahal K, Thompson SG, Cuckle HS. Does breathing other people's tobacco smoke cause lung cancer? Br Med J 1986;293:1217-22.

5 Wald NJ, Boreham J, Bailey A, Ritchie C, Haddow JE, Knight $G$. Urinary cotinine as a marker of breathing other people's tobacco smoke. Lancet 1984; i:230-1.

6 Wald NJ, Ritchie C. Validation of studies of lung cancer in non-smokers married to smokers. Lancet 1984;i:1067.

7 Knight GJ, Wylie P, Holman MS, Haddow JE. Improved 125-I radioimmunoassay for cotinine by selective

8 Thompson SG, Barlow RD, Wald NJ, Van Vunakis H. How should urinary cotinine concentration be adjusted for should urinary cotinine concentration be adjusted for 1990;187:289-96.

9 Biber A, Scherer G, Hoepfuer I, et al. Determination of nicotine and cotinine in human serum and urine: an nicotine and cotinine in human serum and urine:

10 Jarvis MJ, McNeill AD, Russell MAH, West RJ, Bryant A, Feyerabend C. Passive smoking in adolescents: one-year stability of exposure in the home. Lancet 1987;i:1324-5.

11 Lee PN. Lung cancer and passive smoking: association an artefact due to misclassification of smoking habits? Toxicol Lett 1987;35:517-24. 